\title{
POGLED NA KNJIGO LE PARTI DEL DISCORSO GIAMPAOLA SALVIJA
}

\section{Robert GROŠELJ}

Filozofska fakulteta Univerze v Ljubljani

Grošelj, R. (2015): Pogled na knjigo Le parti del discorso Giampaola Salvija. Slovenščina 2.o, 3 (2): $54-62$.

URL: http://www.trojina.org/slovenscina2.o/arhiv/2015/2/Slo2.o_2015_2_o4.pdf.

Giampaolo Salvi, eden najpomembnejših italianistov (med drugim tudi sourednik in soavtor velikih italijanskih slovnic Grande Grammatica Italiana di Consultazione, 1988-1995, 2001, in Grammatica dell'Italiano Antico, 2010), redni profesor na Oddelku za romanistiko Univerze Loránda Eötvösa v Budimpešti, je 2013 (ponatis 2015) objavil knjigo Le parti del discorso (Carocci editore), v kateri pretresa besednovrstno teorijo, v prvi vrsti italianistično.

Knjiga je razdeljena na šest osrednjih poglavij: 1. Kako opredeliti besedne vrste, 2. Tradicionalna klasifikacija besednih vrst, 3. Samostalnik in pridevnik, 4. Zaimki in determinativi, 5. Glagol, 6. Prislovi, predlogi, vezniki; jedro knjige spremljata Uvod in Zaključek. Koliko besednih vrst in katere. Na koncu sledi še izbrana osnovna Bibliografija (137-140).

V Uvodu (7-15) Salvi predstavi namen razprave - posveča se besednim vrstam (tj. skupinam leksemov, ki jih zaznamujejo enake značilnosti; med seboj se povezujejo po določenih pravilih, tvorijo besedne zveze in stavke), in sicer njihovim opredelitvenim značilnostim, ustreznosti tradicionalne in oblikovanju ustreznejše klasifikacije, ki bi jo lahko upoštevali tudi za opis drugih jezikov, ne le italijanskega (14-15).

Poglavje Kako opredeliti besedne vrste (16-32) prinaša preverbo osnovnih opredelitvenih kriterijev - pojmovnega (pomenskega), oblikoslovnega in skladenjskega. Salvi navaja pomanjkljivosti pojmovnega (prim. 
leksikalizacijo vzroka v vezniku perché 'ker', predlogu a causa di 'zaradi', glagolu causare 'povzročiti'; slovnične zgradbe so deloma neodvisne od kognitivnih) in oblikoslovnega kriterija (uspe mu ločiti glagol, imena in nepregibne besede), že uvodoma pa se zavzame za skladenjsko-funkcijski kriterij, ki naj bi kot edini omogočal dovolj natančno klasifikacijo (za razliko od oblikoslovnega), lastno jezikovnemu sistemu (za razliko od pomenskega; 30). ${ }^{1}$ Salvi opozori še na pomen prenosa (traspozicije), s katerim se leksem pojavi v funkciji, ki ni tipična za njegovo besednovrstno pripadnost (27).

V poglavju Tradicionalna klasifikacija besednih vrst (33-39) Salvi predvsem na osnovi klasičnih slovnic Fornaciari (1882) in Serianni (1989) ugotavlja obstoj devetih tradicionalnih razredov besed, ki se delijo na leksikalne (vsebinske) in slovnične (funkcijske), podobne slovničnim morfemom (omogočajo delovanje slovnice; 35). Hkrati opozori na konflikt kriterijev, prim. števnike, ki so lahko zaimki (Quattro mi hanno promesso di venire ‘Štirje so mi obljubili, da pridejo'), pridevniki ( $i$ tre amici 'trije prijatelji') in samostalniki (un milione di voti 'milijon glasov'), besede, ki se uporabljajo kot zaimki (Voglio questo 'Hočem tega') in pridevniki (Voglio questo libro 'Hočem to knjigo') itn. Na tej osnovi se Salvi zavzame za revizijo klasifikacije in predvidi obstoj vzporednih leksikalno-slovničnih razredov glagolov, samostalnikov, pridevnikov in prislovov (38-39).

V poglavju Samostalnik in pridevnik (40-48) Salvi razlikovalno opredeli samostalnik in pridevnik: samostalnik je v osnovi besedna vrsta, ki se pojavlja kot jedro besedne zveze $\mathrm{z}$ določilno funkcijo (prim. sicer določilne pridevnike ob drugotnem prenosu, npr. bratov prihod < brat je prišel), pridevnik pa kot jedro zveze s funkcijo omejevalnega prilastka (v pristavčni prilastkovni funkciji se pojavljajo tudi samostalniki, npr. la zia Maria 'teta Maria' kot ifedeli inglesi

\footnotetext{
1 Nenavadna je izključitev pomenskega kriterija iz jezikovnega sistema. - Skladenjskofunkcijske opredelitve so uvodoma ponazorjene le na samostalniku, glagolu in pridevniku (prim. 25-30).
} 
'zvesti /vsi/ Angleži'). Poleg tega so pridevniki pregibni po spolu² in številu, medtem ko so samostalniki pregibni samo po številu - spol je njihova inherentna kategorija. Salvi opozori še na točke, ki razmejevanje motijo: zveze z izpustom samostalnika; konverzija pridevnika v samostalnik; zloženke, kjer je treba domnevni samostalnik s prilastkovno vlogo (una famiglia modello 'družina vzor’) obravnavati kot del »zapletenega « leksema.

Poglavje Zaimki in determinativi (49-78) je namenjeno izvirni opredelitvi treh razredov besed: naslonk, determinativov in zaimkov. Naslonke so obglagolske prvine, ki funkcijsko ustrezajo določilom ali pa so »prazne« (prim. povratne prvine). $\mathrm{V}$ tradicionalni slovnici gre za osebne zaimke ali (krajevne) prislove (Piero mi porterà allo zoo 'Piero me bo peljal v živalski vrt'; Maria ci si è abituata 'Maria se je navadila na to'; andarsene 'oditi, izginiti'), zgradbeno pa so drugačni - nerazdružljivo so povezani z glagoli. Determinativi so slovnične besede, ki predstavljajo začetni del samostalniške zveze; nanosnika besedne zveze opredeljujejo glede na stopnjo znanega, količino, anaforičnost itn. Formalno so podobni pridevnikom (so ujemalni), zato jih lahko obravnavamo kot slovnični razred pridevnikov. Mednje sodijo (a) kazalni determinativi (krajevni kazalniki tipa questo 'ta', quello 'tisti'), določni člen (nezaznamovani kazalnik, npr. il, la) in oziralni determinativi (tipa cui, il quale 'kateri'),3 ter (b) količinski determinativi (tipa alcuno 'neki', molto 'mnog', poco 'malo'), nedoločni člen (nezaznamovani kvantifikator, npr. un), delni člen (npr. del, dei - jedro besedne zveze ne more biti izpuščeno) in vprašalni determinativi (che 'kateri; kolik', quanto 'kolik'). Kot semi-determinative Salvi opredeli prvinam (a) sorodne deiktične, anaforične pridevnike (stesso

\footnotetext{
2 Nejasna je razlaga (42), da je spol italijanskih pridevnikov vedno izražen z izmenjavanjem -o/-a (prim. felice 'srečen, srečna', pari 'enak, enaka'). Gre morda za eksplicitno razločevalnost?

3 Zanimiva je opredelitev »oziralnega « che kot podrednega veznika - začetni položaj v odvisniku, zgolj brezpredložna raba, pojavlja se le ob relativizaciji osebka, premega predmeta in časovnega prislovnega določila (il giorno che sei venuto 'dan, ko /pribl. ki/ si prišel') - v pogovornem jeziku je anaforično-podredna funkcija »razbita « na naslonko in podredni veznik che (il ragazzo che gli ho parlato - a cui ho parlato; prim. fant, ki sem mu govoril kateremu sem govoril; 73-75).
} 
'isti', tale 'takšen'), ki se pojavljajo tudi na posamostalniškem položaju (za razliko od determinativov) in so vedno omejevalni (za razliko od pridevnikov), in svojilne prvine (mio 'moj', tuo 'tvoj'), ki imajo tudi predikativno funkcijo (za razliko, načeloma, od determinativov), prvinam (b) sorodne pridevniške kvantifikatorje (števnike due 'dva', primo 'prvi'), ki se obnašajo kot deiktični, anaforični pridevniki. Zaimki so slovnična različica samostalnikov, ki jih lahko členimo na enake razrede kot determinative, pri čemer je treba upoštevati še osebne zaimke (io 'jaz', tu 'ti').

Poglavje Glagol (79-108) se ukvarja z glagolskimi oblikami, ki so zaradi posebnih oblikoslovnih značilnosti načeloma neproblematične; izjema so, pričakovano, neosebne glagolske oblike (79). Funkcijsko je glagol besedna vrsta, ki nastopa kot samostojni predikator ali podpira samostalnik/pridevnik $\mathrm{v}$ tej funkciji.4 Glagolske slovnične kategorije so lahko vezane na njegovo oblikoslovje - pregibanje (dejansko stavčne značilnosti, prim. osebo, število, čas, vid, naklon) ali na glagol kot leksem (vrstnost, vezljivost, način). Problem neosebnih glagolskih oblik je odsotnost morfemov za osebo, število in čas, zaradi česar jih Salvi obravnava kot vmesne kategorije - glagolske samostalnike (nedoločnik), pridevnike (deležnik) in prislove (gerundij). ${ }^{5}$ Kot glagolsko opredeljuje njihovo samostojno predikatorsko funkcijo v odvisniških zgradbah ali funkcijo leksikalnih delov zapletenih predikatorskih zgradb (essere, rimanere chiuso 'biti, ostati zaprt'); obenem pa prihaja npr. do prenosa nedoločnika v samostalnik (jedro samostalniške zveze) ali deležnika v pridevnik (ujemanje z osebkom, premim predmetom, samostalniški prilastek).

Poglavje Prislovi, predlogi, vezniki (109-132) se ukvarja z nepregibnimi vrstami, pri čemer Salvi predlaga izvirno členitev. Prislovi so funkcijsko

\footnotetext{
4 Prim. tudi delitev na leksikalne in slovnične glagole (npr. essere 'biti', avere 'imeti', dare 'dati', fare 'delati'), ki »podpirajo « neko drugo besedno vrsto ali sotvorijo različne perifraze (81).

$5 \mathrm{Na}$ glagolskost opozarjajo premi predmet, perfektivne perifraze $\mathrm{z}$ deležnikom pri nedoločniku in gerundiju (aver vinto, avendo invitato), nepopolno ujemanje pri deležniku (102-103).
} 
opredeljeni kot modifikatorji (prilastki) vsega, kar ni samostalnik - ustvarjena je vzporednost $\mathrm{s}$ pridevniki, kar potrjuje tudi oblikovno razmerje med kategorijama (tipa veloce 'hiter' - velocemente 'hitro'); prislovi se delijo na podrazrede, prim. tudi povezovalne prislove (allora 'tedaj', tuttavia 'vendarle'). ${ }^{6} \mathrm{~V}$ osnovi se členitev prekriva s tradicionalno, izjema so prostorski prislovi in del časovnih (ieri 'včeraj', oggi 'danes'),7 ki jih Salvi kljub nepregibnosti uvršča med zaimke - podobno kot samostalniške zveze jih lahko spremlja predlog (la cena di ieri 'včerajšnja večerja /dob. od včeraj/'), funkcijsko so lahko osebki in premi predmeti - določila (Qui è piacevole ‘Tu je prijetno'). V tradicionalni italianistiki sta prislova tudi t. i. profrazi sì 'da' in no 'ne', ki ju Salvi skupaj z medmeti obravnava kot holofrastične prvine, tj. samostojne enote stavčnega značaja. Predlogi vzpostavljajo odvisnostne odnose z drugimi besednozveznimi jedri ali zgradbenimi ravnmi stavka (uvajajo besedne zveze in stavčne zgradbe); gre za preproste slovnične kazalnike odvisnosti (l'arrivo di tuo fratello 'prihod /dob. od/ tvojega brata'), v primeru nepravih predlogov pa za jedra, ki vežejo določilo, oz. dodatne predikatorje, ki natančneje opredeljujejo tip dogodka (Si è messo dietro la balaustra 'Postavil se je za ograjo'). Načeloma se Salvijevi predlogi prekrivajo s tradicionalnimi, pridružujejo pa se jim še nekateri (razmerni) prislovi (prima 'prej', dietro 'zadaj'), ki so obravnavani kot predlogi z neobvezno izraženim določilom, in mnogi podredni vezniki, ki jih Salvi razlaga kot predloge $\mathrm{s}$ stavčnim določilom (perché 'ker', dopo che 'potem ko', mentre 'medtem ko'). ${ }^{8}$ Skladenjski operatorji obsegajo operatorje prirednosti, ki povezujejo prvine

\footnotetext{
6 Prim. načinovne, vršilske (opredeljujejo vršilčevo ravnanje), vrednotenjske, naklonske, ozirne, prislove jezikovnega dejanja. Ob teh razredih Salvi omenja še operatorje fokalizatorje (anche 'tudi', almeno 'vsaj', soprattutto 'predvsem') in nikalnico (logični operator) non (113-115).

7 Drugi časovni prislovi (sempre ‘vedno', mai 'nikoli') se skladenjsko ne obnašajo kot določila ali zunanje okoliščine, temveč kot »pravi« prislovi - npr. njihov skladenjski položaj je med pomožnikom in deležnikom (Non l'hanno mai visto 'Nikoli ga niso videli'; 112).

8 To postane med drugim razvidno ob členitvi tradicionalnih veznikov na zvezo predloga in komplementatorja che 'da' (per 'za', prima 'pred' itn. + che); včasih je komplementatorski del obvezno neizražen (mentre, quando 'ko'), kar pa ne velja za starejše ali narečno stanje (127128).
} 
z enako funkcijo (vezalni $e$, protivni ma, ločni $o$ ), in komplementatorje, ki omogočajo prenos stavčne zgradbe $\mathrm{v}$ besednozvezno. $\mathrm{V}$ tej kategoriji se torej pojavljajo zgolj nekateri tradicionalni vezniki (che 'da', se 'ali, če'), a se jim pridružujejo še izbrani predlogi (z zadržkom, npr. di, da). Salvi na koncu poglavja (132) opozori na provizoričnost členitve in na njeno morebitno izboljšavo: pridevniki in prislovi bi se lahko združili v en razred; predlogi, ki so slovnični kazalniki odvisnosti, bi lahko sodili med skladenjske operatorje itn.

Salvi v poglavju Zaključek. Koliko besednih vrst in katere (133-136) poudari, da je treba pri besednovrstni klasifikaciji kot ključni kriterij upoštevati slovnične značilnosti, $\mathrm{v}$ prvi vrsti skladenjske funkcije. Te omogočajo vzpostavitev osmih besednih vrst: samostalnik (določilo, zunanja okoliščina); prideunik in prislov (samostalniški in nesamostalniški prilastek); glagol in predlog (glavni in dodatni predikator); skladenjski operator (slovnični kazalnik); medmet, profraza (stavek). Pri samostalniku, pridevniku in glagolu Salvi omenja še leksikalno-slovnične podrazrede (prim. zaimki, determinativi, pomožniki), ki jih vzpostavljajo bolj specifične značilnosti. Nekoliko nedorečeni ostajajo naslonski zaimki, ki so »vmesna kategorija « in domnevno »ne sodijo v to klasifikacijo .

Salvijevo členitev besednih vrst lahko označim kot skladenjsko, pri čemer gre za natančno (predvsem funkcijsko in distribucijsko) analizo skladenjskih zgradb, v katerih se leksikalne prvine, kot predstavnice besednih razredov, pojavljajo; pomenski in oblikoslovni kriterij sta potisnjena v ozadje. Gre za - po mojem védenju - izvirno besednovrstno kategorizacijo, ki jo Salvi vedno utemeljuje in objektivizira, tudi z ustreznimi zgledi. Obenem opozarja, da je členitev še vedno odprta, kar ponazori tudi z možnimi spremembami oz. dopolnitvami.

Prvo problemsko vprašanje ob Salvijevi razpravi se nanaša na (1) načelno skladenjsko opredelitev besednih vrst. V kolikor namreč besedne vrste - kot jezikoslovni pojem - sodijo v slovar in v slovnico, bi bilo treba pri njihovem 
opredeljevanju upoštevati tudi pomenske in oblikoslovne značilnosti. $\mathrm{Na}$ uporabnost npr. pomenskega kriterija kažejo med drugimi tudi funkcionalistične obravnave (npr. Morley 2000: 31-52; Anward 2001), odprto vprašanje pa je, ali oz. kako se lahko posamezni kriteriji izpopolnijo.

Druge točke, ki se mi zdijo problemsko odprte, so povezane s posameznimi členitvami; ob tem je treba opozoriti, da lahko nanje vpliva tudi izjemno kompaktna in kompleksna obravnava. Nejasna ostaja (2) besednovrstna pripadnost naslonk - gre za posebno kategorijo, za poseben (slovnični) podrazred samostalnikov ali podrazred zaimkov? Vprašljiva je (3) uvrstitev krajevnih in nekaterih časovnih prislovov med zaimke, tj. med »slovnične samostalnike «, in sicer zaradi naslednjih lastnosti: tako kot ostali prislovi so lahko določila ali dopolnila (odvisno od predikatorja, npr. Si comporta bene 'Obnaša se dobro'); tudi drugi prislovi se lahko uporabljajo s predlogi (di troppo 'preveč', per quanto 'glede na to, koliko'); raba na položaju osebka ali premega predmeta je lahko posledica prenosa; njihove zveze običajno razvijajo prislovi, kar bi kazalo na nesamostalniškost (qui accanto 'tu poleg', li vicino 'tam blizu') in, posredno, na nezaimenskost. Zdi pa se, da vendarle predstavljajo poseben podrazred prislovov. (4) Nekateri tradicionalni predlogi imajo glede na skladenjsko rabo dvojno besednovrstno pripadnost: l'arrivo di mio fratello 'prihod mojega brata' (predlog) in Piero progetta di partire domani 'Piero načrtuje odpotovati jutri’ (skladenjski operator, ko uvaja stavčno zgradbo). Problemsko zanimiva je tudi (5) uvrstitev zvez iz predloga in (neobvezno izraženega) komplementatorja (tradicionalni podredni vezniki tipa perché = per + che, mentre $=$ mentre $/+$ che $/$ ) med predloge - zaradi predložnega jedra zveze? Na nekatere druge nejasnosti je bilo že opozorjeno (v op. 1 in 2).

Kljub problemskim točkam je izvirna besednovrstna členitev G. Salvija - po mojem mnenju - izjemno zanimiva zaradi večplastne skladenjske analize, ki upošteva funkcijske, odvisnostne, vezljivostne, distribucijske parametre. Tovrstna obravnava, ki se od Toporišičeve večinoma razlikuje (prim. Toporišič 1974/1975; 2004), bi lahko usmerjala tudi nov in bolj poglobljen skladenjski opis slovenskih besednih vrst ter podvrst. 


\section{LITERATURA}

Anward, J. (2001): Parts of speech. V M. Haspelmath, E. König, W. Oesterreicher, W. Raible (ur.): Language Typology and Language Universals 20/1: 726-735. Berlin, New York: Walter De Gruyter.

Morley, G. D. (2000): Syntax in Functional Grammar. An introduction to lexicogrammar in systemic linguistics. London, New York: Continuum.

Toporišič, J. (1974/75): Esej o slovenskih besednih vrstah. Jezik in slovstvo, 20(8): 295-305.

Toporišič, J. (2004): Slovenska slovnica. Maribor: Založba Obzorja. 


\section{A REFLECTION ON THE BOOK LE PARTI DEL DISCORSO BY GIAMPAOLO SALVI}

To delo je ponujeno pod licenco Creative Commons: Priznanje avtorstvaDeljenje pod enakimi pogoji 2.5 Slovenija.

This work is licensed under the Creative Commons Attribution ShareAlike 2.5 License Slovenia.

http://creativecommons.org/licenses/by-sa/2.5/si/

(c) () 